\title{
Bettina Sidy
}

Profesora en enseñanza media y superior en Ciencias Antropológicas, Facultad de Filosofía y Letras, Universidad de Buenos Aires. Doctoranda de la Universidad de Buenos Aires. Becaria doctoral CONICET. Integrante del Proyecto UBACyT F091 "Cambios y continuidad en la sociedad indígena e hispano-criolla" (2008-2010), doctoranda. Integrante del Proyecto "Sobre alteridades, pasados y presentes: procesos de constitución de la memoria y la identidad en poblaciones indígenas del Noroeste argentino y la región Patagónica desde el siglo XIX al presente". (Dirección: Dra. Carolina Crespo y Dra. Lorena Rodríguez, 2008-2010 Programa de Reconocimiento Institucional a Equipos de Investigación de la FFyL, UBA (CD - Resolución No 3223/08.) Pertenencia institucional: Universidad Nacional de Buenos Aires, Facultad de Filosofía y Letras, Sección Etnohistoria, Instituto de Ciencias Antropológicas / Universidad Nacional de San Martín, Instituto de Altos Estudios Sociales.

b_sidy@yahoo.com.ar 


\title{
Resumen
}

Hacia mediados del siglo XVIII Buenos Aires vivió importantes transformaciones urbanas producto de cambios sociales, económicos y demográficos. Analizaremos la relación que se estableció entre las diversas problemáticas derivadas del crecimiento urbano y las medidas de gobierno enunciadas en este sentido entre 1740 y 1762 a partir de los bandos publicados por los gobernadores rioplatenses. Buscamos observar cuáles eran sus principales preocupaciones y a qué tipo de soluciones se apelaba en cada caso. Nos interesa explorar en torno a las contradicciones que se presentaron entre las posibilidades y prácticas concretas y el tipo de organización ideal que se buscaba imponer. Para ello nos enfocaremos en los bandos que hacían referencia a los usos de los espacios físicos y al control en relación con la creciente población urbana.

\section{Palabras clave}

Gobierno, Buenos Aires, Ciudad colonial, Transformaciones urbanas.

\begin{abstract}
$\underline{\text { Abstract }}$
During the middle of the $18^{\text {th }}$ Century Buenos Aires experienced important urban transformations as a result of social, economic and demographic changes. The aim of this study is to analyze the relationship established, through the "bandos" (decrees) of River Plate Governors, between diverse problems resulting from urban growth and related government measures between 1740 and 1762 . We seek to observe what were the governors' main concerns and what kind of solutions they appealed to in each case, in order to explore the contradictions that arose between possibilities and concrete practices and the ideal urban organization they seeked to impose. To do this we focus on the decrees which referred to the uses of physical spaces and their control in relation to the growing urban population.
\end{abstract}

\section{Kev words}

Governors, Buenos Aires, contradictions, Urban transformations. 
Crecimiento y control de la vida urbana.

Un análisis de los bandos de Gobierno en el Buenos Aires colonial (1742-1762)

\section{INTRODUCCIÓN}

El presente trabajo se centra en la ciudad de Buenos Aires a mediados del siglo XVIII y en la relación que se estableció entre el espacio social de la urbe y el ejercicio del gobierno en un contexto de cambio. Los estudios sobre la ciudad en su etapa colonial se enfocan, en su mayor parte, en el período que comienza con las improntas borbónicas de fines del mencionado siglo. Sin embargo, creemos que desde 1740 podemos observar en Buenos Aires una serie de transformaciones como producto de la conjunción de cambios sociodemográficos y económicos y de la implementación de medidas de gobierno locales y metropolitanas.

Las ciudades coloniales se organizaban sobre la base de un planteo de segregación habitacional, dentro del cual los diferentes estamentos que componían la sociedad debían ocupar determinados espacios en la trama urbana. Sin embargo, siempre existió una distancia entre el ideal estamental y la práctica concreta. Nos proponemos indagar en la relación que se estableció entre los diversos usos de los espacios urbanos y las medidas de gobierno enunciadas en este sentido, en un contexto de profundas transformaciones.

En particular se examinará el desarrollo de dichas medidas en el transcurso de los veinte años comprendidos entre 1740 y 1762 , para advertir desde qué perspectivas y objetivos se enunciaban las políticas de gobierno sobre el espacio urbano. Se analizarán los bandos de buen gobierno y los autos particulares emitidos por los gobernadores rioplatenses ${ }^{1}$, en los que se hacía referencia al ordenamiento y regulación de la vida urbana. Consideramos relevante indagar dichos documentos, ya que reflejan una impresión directa de la realidad sobre la que se legislaba, brindándonos así una imagen de las condiciones de vida en la ciudad, dándonos una pauta del tipo de organización urbana que se buscaba imponer. Asimismo en dichos documentos se manifiestan diversos indicadores de la modalidad de crecimiento urbano, la cual traerá consigo diferentes medidas de control, organización o reparación de los espacios públicos, que siguiendo la documentación disponible para la ciudad de Buenos Aires podemos ubicar a partir de 1740, año en que los gobernadores porteños comenzaron a emitir con mayor asiduidad y recurrencia bandos de gobierno dirigidos a ordenar diversos asuntos relativos a la convivencia urbana. Se desarrollaron políticas tendientes al mejoramiento de las calles, el control de la basura, del tránsito, la iluminación nocturna y la seguridad en las calles, en un intento por parte de los gobernadores de imponer un orden que estuviera en consonancia con la ideología vigente.
1-Durante el periodo mencionado fueron gobernadores: don Domingo Ortiz de Rozas (1742 1745), don José de Andonaegui (1745-1755), Alonso de la Vega (interino) y don Pedro de Cevallos (1756-1766). 


\section{BUENOS AIRES EN EL SIGLO XVIII}

2- A comienzos del siglo XVIII el Estado español se encontraba debilitado. La guerra de sucesión (1701-1713) en la que se habia envuelto a principios del XVIII terminó por provocar una profunda crisis económica y política, y el naciente desarrollo del capitalismo industrial inglés comenzaba a afectar seriamente el comercio marítimo de las colonias españolas en América.
En el transcurso del siglo XVII la ciudad de Buenos Aires fue sucesivamente descrita como una pequeña aldea que contaba con pocos edificios construidos, un puerto ruinoso y una elite cuya calidad podía ser considerada como precaria en relación con otras ciudades hispanoamericanas (como Lima, México e incluso Asunción o Tucumán). En definitiva, un fuerte de pocos recursos tanto humanos como materiales. Ahora bien, durante el transcurso del siglo XVIII esta imagen comenzó lentamente a variar.

Al relevar la bibliografía sobre el Buenos Aires colonial, vemos que gran parte de los autores ubican las mayores transformaciones hacia el final del siglo XVIII, como producto del paquete de reformas borbónicas que incluyó la elevación de la ciudad a capital virreinal. Sin embargo, coincidimos con Magnus Mörner (1959) y con TAu ANZó́tegui (1992b), quienes sostienen que dichas transformaciones formaron parte de un proceso de más largo alcance, y consideramos que si bien se vinculaba fuertemente con el contexto internacional asumió también características propias en el ámbito rioplatense.

En el año 1695 Buenos Aires adquirió el rango de capital de la gobernación (BERNAND,1997) y conoció el inicio de un período de desarrollo en diversos planos (demográfico, político, económico) que la condujo a su vez a concentrar energías en el crecimiento interno, ya que paulatinamente fue dejando de ser un espacio político marginal dentro del plan metropolitano (Morse, 2004). Dicho desarrollo estuvo íntimamente vinculado con la posición estratégica de Buenos Aires. Por aquellos años el Río de la Plata se convirtió en una zona central en el conflicto entre España y Portugal y en una pieza clave en torno a los nuevos parámetros de competencia mercantil europeos. ${ }^{2}$ La corona española desplegó en la zona una gran empresa militar y naval y una política económica que permitiera a la región generar las rentas necesarias para mantener dicha empresa (CHIARAMONTE, 2005).

En el plano económico comenzó un "proceso de Atlantización” (Miletich, 2000) como respuesta a las necesidades de la corona para reforzar el flanco débil de su imperio sometido a presiones por parte de otros países europeos. A partir de 1740 Paraguay, Cuyo y el Río de la Plata (e incluso parcialmente Tucumán) orientaron su producción a Buenos Aires, que se convirtió en un polo de articulación entre las regiones productoras, las economías regionales y el puerto. Las actividades comerciales comenzaron a repercutir sobre la fisonomía de la ciudad, aunque el proceso de "modernización" fuera lento. La imagen de la ciudad era todavía la de una aldea polvorienta y sucia y el puerto seguía siendo miserable y precario.

Cuaderno Urbano. Espacio, Cultura, Sociedad - Vol. 10 - N 10 (Junio 20II)- Pp. 04I-06I - ISNNI666-6186 
Crecimiento y control de la vida urbana. Un análisis de los bandos de Gobierno en el Buenos Aires colonial (1742-1762)

Sin embargo, el dinamismo comercial que adquiría la ciudad funcionó como un importante atractivo para aquellos forasteros en busca de nuevas oportunidades (socolow, 1991).

Buenos Aires por su situación geográfica, estratégica y por su lento desarrollo, fue propicia a la llegada de extranjeros ${ }^{3}$, sin licencia real, los cuales eran considerados ilegales. ${ }^{4}$ $\mathrm{Su}$ ingreso y permanencia fueron regulados con criterios restrictivos desde la península, y numerosos bandos de gobierno dan cuenta de las intenciones de expulsión por parte de las autoridades locales, aunque es justamente la reiteración de los mandatos lo que nos permite dudar acerca de su efectividad. Por otro lado, si bien el arribo de esclavos fue una constante desde el siglo XVII, a partir del tratado de Utrech (1713), por el cual la Compañía Británica se hizo cargo de la trata, se estimuló un crecimiento en relación con la incorporación de gente de color a la sociedad porteña que en 1744 ya representaba el $16 \%$ de la población local (SANTAMARÍA, 2000).

El ingreso y la permanencia de grupos de diversos orígenes en el Río de la Plata estuvieron determinados también por las características propias de la estructura laboral del área. Los españoles despreciaban las labores mecánicas y artesanales por considerarlas por debajo de su estatus personal, por lo cual se abrieron las puertas a quienes tuviesen alguna especialización en oficios o pudiesen realizar las tareas necesarias para el mantenimiento de la ciudad.

Diversos autores reseñan el crecimiento numérico de la población, cuando a principios del XVII no había más de mil personas, para 1720 ya eran 8908 los habitantes (GUTMAN Y HARDOY, 1992: 42), y los números siguieron progresando: para 1744, la ciudad contaba ya con 11.600 habitantes (JoHnSON y SOCOLOw, 1980: 332). Junto con el crecimiento de la población se extendió también el área construida en la ciudad. HARDOY y GUTMAN explican que para 1730 se comenzaron a cocer ladrillos y tejas, lo que permitió reemplazar el adobe y la paja en las viviendas, y para el año 1760 la ciudad estaba compuesta por unas setecientas cuadras con distintos grados de ocupación.

Por definición, en las ciudades la convivencia y el contacto entre estratos sociales abarca la totalidad del espacio. En el caso particular de las ciudades coloniales, amos y esclavos compartían no solo las plazas, los mercados, las calles, sino también el mismo ámbito habitacional. Entre los grupos sociales se establecían diversas redes de interdependencia y necesidades mutuas. El "bajo pueblo" vivía en una zona de circulación y de mediación: la calle, los lugares públicos, las pulperías, las tabernas, las plazas; sitios que le brindaban
3- Originalmente eran extranjeros todos aquellos que no fueran nacidos en los reinos de León de Castilla. Sin embargo, a lo largo de los años, el concepto de extranjería fue en la práctica una realidad difusa y cambiante, como lo era la misma nacionalidad española (LOCKHART, JAMES 1982 / OTS CAPDEQUÍ, JOSE MARÍA, 1940)

4- Durante los siglos XVI y XVII se emitieron distintas cédulas reales que fueron estableciendo limitaciones y prohibiciones para la entrada y residencia de los la entrada y residencia de los extranjeros. Fueron recogidas en la Recopilación de 1680 (Libro IX título XXVI). Los extranjeros no podían pasar a las Indias, tratarn contratar. Pero el cumplimiento de esto fue muchas veces dispensado por vías legales o de hecho (TAU ANZOÁTEGUI, V 1992b). 
5- El estatus de vecino era reservado a aquellos propietarios de origen español que, entre otras prerrogativas, accedian a ocupar los cargos públicos en el Ayuntamiento.

6- Porque además, tampoco debemos pensar en el grupo de vecinos como si fuera un todo homogéneo, dentro de las elites coloniales se desarrollan todo tipo de rivalidades en torno de preeminencias políticas y también mercantiles que van a afectar al grupo marcando diferencias de todo tipo. un espacio de independencia y cierto anonimato, aunque limitado en el caso de los negros, por la visibilidad del color (BERNAND, 2003). Las trabas puestas a los desplazamientos de las clases bajas podían resultar efectivas en las pequeñas ciudades, pero a medida que se imponía el crecimiento urbano iban desapareciendo y los grupos subalternos se fundían con otros.

Como correlato, numerosos bandos de gobierno intentaron limitar los desplazamientos nocturnos de las clases bajas. Sin embargo, el control de ciertos lugares, como las pulperías, resultaba muy difícil tanto porque iba en contra de los intereses del comercio, como porque los vecinos ${ }^{5}$ no frecuentaban esos sitios. Cuestión sumamente interesante a la hora de analizar la circulación urbana, ya que "el bajo pueblo" resultaba una presencia necesaria a lo largo de la totalidad de la ciudad, por los servicios indispensables que brindaba para el funcionamiento efectivo de la vida urbana, como aguateros, lavanderas, vendedores ambulantes, etc. En este sentido, dicho sector de la población adquirió una movilidad que lo habilitó a "trastornar" el planteo inicial de segregación espacial, aunque no dejaba de generar un cierto grado de aversión y temor en las clases dominantes que cristalizaban en diversas medidas de control, ya sea desde el gobierno (con sus diferentes niveles) como desde los propios habitantes, con distintos grados de intervención, aceptación o tolerancia. ${ }^{6}$

En este contexto, nuevos actores sociales influyeron de maneras significativas en la organización de los espacios urbanos, y estas transformaciones a su vez generaron conflictos dentro del entramado político. Más allá de las reglas de juego imperantes, se producían brechas en el interior mismo de los cuerpos sociales, se disputaban espacios y concepciones en torno a cuestiones como la movilidad social y el control de la población.

Cabe destacar aquí desde qué concepción ideológica fueron fundadas las ciudades hispanoamericanas, para lograr una mejor contextualización de los procesos que van a atravesar la vida cotidiana de Buenos Aires.

\section{LAS CIUDADES COLONIALES}

Desde los inicios de la colonización en América, las ciudades se constituyeron en los focos de concentración del poder, asegurando la presencia de la cultura europea y dirigiendo los procesos económicos, sociales y políticos en las colonias. El trazado cuadricular conllevaba la idea de una jerarquización del espacio urbano. Desde lo ideológico, se intervenía en el espacio demarcando zonas de poder e influencia con la intención de lograr transponer y 


\section{Crecimiento y control de la vida urbana. Un análisis de los bandos de Gobierno en el Buenos Aires colonial (1742-I762)}

equiparar la delimitación urbana a la delimitación estamental de las sociedades del Antiguo Régimen (De Solano, 1990). El control de la elite idealmente se sostenía y era a su vez sostenido por la demarcación y por el ideal de segregación territorial según el cual cada ciudad era fundada.

Pero, tal como lo indica Romero (2001), esta concepción urbanística se ubicaba en el plano ideológico, en la praxis, la realidad social y cultural en Hispanoamérica resultaba disímil y caótica, generándose así una fisura entre lo ideal y la práctica que fue una realidad concreta ya desde los comienzos de la colonización, extendiéndose además a las políticas de gobierno implementadas en cada ciudad en particular.

En el plano ideológico, la organización social en las ciudades coloniales se encontraba basada en un orden de tipo estamental (HoBERMAN y Socolow, 1992). El origen étnico, la ocupación, la identidad y la pertenencia a una corporación determinaban la posición de cada individuo en la sociedad. Sin embargo, autores como Nidia ARECES (2000) y BEATRIZ RuIBAL (2000) indican que si bien las ciudades coloniales se estructuraban a partir de un régimen estamental de antiguo orden, esto no lograba evitar que se produjeran procesos de "mestización cultural", lo cual se encontraba íntimamente vinculado con la naturaleza misma de la vida urbana.

La ciudad se convirtió en el espacio por excelencia donde los frecuentes e inevitables contactos, la violencia y la movilidad social desafiaron constantemente el orden tradicional. En este sentido, existió una contradicción entre un espacio social que era "regulado" y a la vez "móvil" y donde se generaron conflictos, relaciones e intercambios entre los distintos sectores de la sociedad, que tuvieron también un correlato en las medidas de gobierno. En paralelo al crecimiento y diversificación de las ciudades coloniales en cuanto a su población, inevitablemente la traza inicial y los usos de la misma sufrieron también modificaciones. Dichas transformaciones chocaban con el ideal metropolitano según el cual la jerarquización espacial debía coincidir con las diferenciaciones estatutarias vigentes.

En el plano ideológico se establecía una profunda vinculación entre la organización del espacio social de la ciudad, el comportamiento que se esperaba de sus habitantes, o por lo menos al que se aspiraba desde las esferas del poder político, y las medidas de gobierno efectivamente enunciadas. Sin olvidar que estas, a su vez, estaban atravesadas por los diversos conflictos y pujas que se sucedían entre los representantes del poder político, en un contexto en que todos los órganos de gobierno se encontraban vinculados entre sí y con la elite (Moutoukias, 2000). 
$\overline{7-E l ~ c a r g o ~ d e ~ t e n i e n t e ~ d e l ~ r e y ~}$ se implementa en las colonias americanas a comienzos del siglo XVIII. Tiene también una importante jurisprudencia política. Será el encargado de reemplazar al el encargado de reemplazar al gobernador en caso de ausencia y es quien preside el cabildo de la ciudad en que esté. Si bien dependian del gobernador, gozaban de un poder excepcional en el medio en que gobernaban (BEATO, 2005).

8- Lo mismo comienza a producirse en otras ciudades hispanoamericanas, por ejemplo en Lima y Ouito. PEREZ CANTÓ, M. P. y Quito. PEREZ Lima en el siglo XVIII. Estudio socioeconómico. Ediciones de la Universidad Autónoma de Madrid, Instituto de Cooperación Iberoamericana Madrid RAMOS GOMEZ L. (2005) "Enfrentamientos entre grupos Enfrentamientos entre grupos de poder por el dominio del Cabildo de Quito entre 1735 y 1739 ". En: Revista complutense de historia de América, Vol. 31 53-77.
Consideramos que la asiduidad con que los gobernadores porteños emitieron bandos de gobierno a partir de la década de 1740 estaba en estrecha relación con el deseo de las autoridades de establecer patrones de conducta social apropiados al régimen estamental vigente. Frente al contexto de crecimiento por el que transitaba Buenos Aires, las autoridades vieron necesario desarrollar nuevos mecanismos de control social.

\section{EL GOBIERNO DE LA CIUDAD}

En cuanto a la organización política tradicional dentro de las ciudades coloniales, cabe destacar el papel preeminente que se asignó a los Cabildos ya desde los comienzos de la colonización. Así como las ciudades se establecieron como los núcleos básicos del sistema político colonial, no se concebía la ciudad sin su consiguiente Cabildo (BEATo, 2005). Sin embargo, para mediados del siglo XVIII, Víctor TAU ANZOÁteguI (1976) sugiere que el poder de los Cabildos en el actual territorio argentino comenzó a ser de alguna manera contrarrestado por las figuras del gobernador y del teniente del rey. ${ }^{7}$ Como ya observamos, se produjo un salto en la cantidad y calidad de los bandos emitidos por los gobernadores que hacen referencia al cuidado y control del orden urbano, cuestiones que anteriormente constituían la jurisdicción casi exclusiva del Cabildo. ${ }^{8}$ Para el caso de la ciudad de Buenos Aires, encontramos en la documentación estudiada diversos reclamos y pedidos realizados por el Cabildo y por el Procurador General que serán respondidos y aprobados por los gobernadores, con lo cual podemos suponer que si bien el poder del ayuntamiento se encontraba en decadencia con respecto a sus atribuciones previas, mantenía una importante injerencia en los asuntos urbanos.

En este contexto de transformaciones y tensiones, cada uno de los actores políticos (entendidos en términos corporativos) buscó reafirmar su posición (Socolow, 1987). Los choques que se produjeron entre los capitulares y el gobernador tenían en general como escenario "el espacio social de la ciudad", es decir, temas como: la distribución de tierras, el cuidado edilicio y sanitario de la ciudad, la conservación e inspección de cárceles y hospitales, el control del abasto, la regulación del comercio, la manutención del orden público, es decir, lo que "configuraba el gobierno 'por menor' de la ciudad" (MARTIRÉ y TAu Anzó́tegui, 2003: 97).

Los bandos de gobierno fueron los elementos que los gobernadores hispanoamericanos utilizaron para legislar sobre estas cuestiones. En términos analíticos, TAU ANZOÁTEGUI (1992a) nos indica que los bandos de gobierno reflejan el "nivel más popular" del ordenamiento jurídico, tanto porque se aplicaban a todos los grupos sociales como porque el 


\section{Crecimiento y control de la vida urbana.} Un análisis de los bandos de Gobierno en el Buenos Aires colonial (1742-I762)

conocimiento de sus normas llegaba a los distintos estratos de la sociedad. ${ }^{9}$ Precisamente por ello es el nivel de legislación que más pudo influir sobre la conducta de la población analfabeta. En la documentación se hace referencia al control de la población en sus actividades y de los espacios considerados como públicos — las calles, las plazas, los mercados-, como también en lo relativo a los usos cotidianos de la ciudad. Se trata de textos de una extensión reducida, en los que las disposiciones están formuladas de manera sencilla y recurrente. ${ }^{10}$

Según BARRENECHE (2001) los bandos nos ilustran sobre la manera en que el gobierno colonial definía la buena conducta y la responsabilidad de los porteños, su contenido conlleva la idea de que el control social no podía ser solo responsabilidad del Estado colonial, sino que también requería de la participación de los vecinos. En términos metodológicos, al reconocer el carácter legislativo relativamente inmediato de los bandos, por su cercanía con los conflictos urbanos, es posible entrever en las materias sobre las que legislaba y la periodicidad con la que aparecían,cuáles eran las preocupaciones y los conflictos en la sociedad porteña y también cuál era el carácter de las soluciones a las que se apelaba.

Para lograr los objetivos propuestos y poder observar desde qué perspectivas los gobernadores intervenían en la organización de los espacios y de los quehaceres urbanos, introduciremos el análisis de la documentación a partir de tres grandes temas. En principio, nos enfocaremos en los bandos que hacen referencia a los usos, el cuidado y la organización de los espacios físicos de la ciudad. En segundo lugar, observaremos el tipo de control que se buscó implementar en relación con la creciente población urbana. Por último, tomaremos como ejemplo los conflictos asociados con las percepciones en torno a la seguridad urbana desde la perspectiva del gobierno. Cabe aclarar, sin embargo, que dichas temáticas se encuentran profundamente vinculadas entre sí, y que el objetivo fundamental de esta organización es el de facilitar las tareas de análisis.

\section{LA ORGANIZACIÓN DEL ESPACIO}

En relación con los usos y apropiaciones de los espacios urbanos realizados por diversos actores sociales en el transcurso de los años, diferentes preocupaciones impregnaron los mandatos gubernativos. La prohibición de andar a caballo por la noche, de portar armas, el establecimiento de horarios de cierre para las pulperías, la veda a los juegos de cartas en tiendas, a las corridas de parejas en días de trabajo y: “... los juegos de bola (...) que hay en diferentes canchas de esta ciudad y de bolos se experimenta el perjuicio y desorden de que en los días de trabajo se juntan a jugar los sujetos que deben acudir al trabajo diario faltando a él y a la atención de su familia". ${ }^{11}$
9- Los documentos cuentan con una cláusula final que certifica su publicación: "Y para que llegue a noticia de todos y que ningu pretenda alegar ignorancia se publicará a son de cajas de guerra y en los parajes públicos acostumbrados de esta ciudad". Bando del gobernador D. Ortiz de Rozas, Buenos Aires, 03-07-1742. Rozas, Buenos Aires, Archivo General de la Nación -Argentina-, en adelante: $A G N-A-$ IX-8-10-1 Folios: 7-8.

10- TAU ANZOÁTEGUI trabaja especialmente con los denominados de "Buen Gobierno" que regulaban de "Buen Gobierno" que regulaban
sobre una variedad de materias y los diferencia de los bandos o autos particulares que constaban de una sola norma, aunque esta fuese de las que habitualmente eran contenidas en aquel.

11- AGN IX-8-10-2 Folio 262 Bandos del gobernador $P$. de Cevallos, 18-11-1756, AGN -AIX-8-10-2 Folios: 150-152. 09-081759, $A G N-A-; I X-8-10-2$ Folios. 194-195. 
12- Bando del gobernador $J$. de Andonaegui, Buenos Aires, 22-06-1746, AGN - A-; IX-8-10-1 Folios: $96-97$

13- Reclamo realizado por don Francisco Antonio de Goicoechea don Andrés de Esquinas, doña Roza Giles, 11-09-1761, AGN-AIX-8-10-2 Folio: 265-266; 267; 268-269. Bando del gobernador interino J. Larrazábal, Buenos Aires, 11-09-1761, AGN -A- IX8-10-2 Folio: 270-271.

14- Bando del gobernador D. Ortiz de Rozas, Buenos Aires, Ortiz de Rozas, Buenos Aires, Folios: 7-8.

15- Bando del gobernador $J$. de Andonaegui, Buenos Aires, 10-01-1747, AGN -A-; IX-8-10-1 Folio: 113 .

16- Bando del gobernador $J$. de Andonaegui, Buenos Aires, 12-05-1747, AGN -A-; IX-8-10-1 Folio: 122 .

17- Bando del gobernador $J$ de Andonaegui, Buenos Aires, 12-05-1747, $A G N-A-; I X-8-10-1$ Folios: 122-123.
Estos mandatos se reiteraron constantemente, en un intento sostenido por controlar el modo en que los porteños utilizaban y se desenvolvían en el espacio urbano. En cada caso, se invocaron la seguridad y bienestar del vecindario, contra el perjuicio y el desorden que generaba el incumplimiento de lo mandado. A su vez, los gobernadores buscaron controlar a los vagamundos y holgazanes obligándolos a conchabarse o en su defecto a salir de la ciudad. ${ }^{12}$ El vagamundo, como se verá más adelante, fue el paradigma de lo incontrolable, y como tal un elemento peligroso para el orden social.

Junto a la seguridad que se buscaba en las calles, los gobernadores se preocuparon también por la limpieza, el aseo y la composición de las veredas. Con el correr de los años, los bandos en relación con estos temas se volvieron más precisos, señalando cuestiones como cuáles eran las calles más transitadas y cuál era el curso que debían llevar los desagües de la ciudad. ${ }^{13}$ Se ordenó que no se echaran animales muertos ni ropas de difuntos por las calles o en la orilla del río ${ }^{14}$, se reguló el lugar desde el cual los aguateros debían recoger el agua, se mandó a los pulperos a que colocasen faroles en las puertas de sus tiendas en el horario nocturno. En 1747 Andonaegui ordenó a los vecinos que mataran a sus perros quedándose solo con uno ${ }^{15}$. Sin embargo, el estado de la ciudad continuaba siendo bastante pobre. En el mismo año el gobernador advirtió que debido a las lluvias, las calles se habían vuelto tan intransitables que no se podía "ni llegar a las iglesias, quedando muchos sin poder cumplir con el precepto..." "16, y por ello ordenaba que todos los vecinos cada uno en su pertenencia "componga una barra de las paredes para afuera de la calzada de ladrillo o piedra" para que se pudiera transitar, y lo exigía a la brevedad ya que sería en beneficio de los dueños de otras casas y de la "causa pública", ya que "es esta una política que se practica en todas las ciudades para que el trajín de los caballos no deshaga las calles". ${ }^{17}$ En estas frases podemos observar cómo aparecía un interés por el cuidado y la composición de las calles y cómo la ciudad de Buenos Aires comienza a pensarse en espejo de otras ciudades más importantes dentro del imperio español. El hecho de que fueran los vecinos mismos quienes se debían hacer cargo de la composición hace visible el modo en que en el Antiguo Régimen no existía una división tajante entre lo que era considerado público y lo privado, y además ilustra sobre la forma en que la responsabilidad por el orden demandaba la intervención de los vecinos. A lo largo de los años se sucedieron otros bandos muy similares, y en todos será responsabilidad de los vecinos componer las calles y las calzadas. Un año después, en respuesta a un pedido del Procurador General, el gobernador advertía: "... lo infestas que se hallan sus calles de ella de las basuras que arrojan como también de los animales muertos y otras cosas fétidas y albañales y que de estos proviene la corrupción y peste infestando los aires y para que esto se evite y de que por las calles no anden cerdos que son los que (...) causan el mal olor como también que los aguateros 


\section{Crecimiento y control de la vida urbana.} Un análisis de los bandos de Gobierno en el Buenos Aires colonial (1742-1762)

cojan el agua del río media cuadra adentro y no de los pozos donde van a lavar o de las orillas y cuya agua puede ser causa de algunas enfermedades por las cosas inmundas que lavan en dichos pozos...". ${ }^{18}$

En conjunción con las problemáticas derivadas del aseo e higiene de la ciudad, las autoridades buscaron también organizar/controlar aquellos espacios "vacios" que eran utilizados tanto para depositar los desechos como para encubrir las actividades de los individuos “indeseables" de la sociedad. En marzo de 1753, en respuesta a un pedido del Cabildo, el gobernador Andonaegui advertía que: “... esta ciudad hay sitios sin poblar ni vender que solo sirven (...) cometerse en ellos maldades y (...) algunos - facinerosos-viéndose perseguidos por la justicia se escapan por ellos. Para evitar estos inconvenientes (...) Ordeno y mando que todas las personas que tuvieren otros sitios los pueblen o cerquen o los vendan para que otras personas los edifiquen". ${ }^{19}$

Lo que debían cumplir en el plazo de un año. Por un lado, vemos un interés porque la ciudad adquiera una forma más organizada, o por lo menos edificada, que además pudiera dar cobijo a la creciente población porteña; por el otro, la inseguridad, la delincuencia que aparece recurrentemente como justificación. Se hace visible aquí cómo las autoridades buscaban ordenar el uso del espacio urbano limitando la intervención/actuación allí de ciertos elementos sociales que consideran "indeseables". Sin embargo, en septiembre del mismo año, el gobernador extendió el plazo, tras advertir que ningún vecino había cumplido con lo ordenado.

A pesar de los mandatos emitidos, los problemas continúan a lo largo del tiempo. Tanto es así que en 1755 el gobernador interino Alonso de la Vega emitió un bando de buen gobierno dedicado exclusivamente al tema del aseo, arreglo y compostura de las calles. En él se ordenaba con detalle sobre los lugares aptos para arrojar las basuras: "entendiéndose que no son muladares los huecos que lindan con las calles principales ${ }^{20 "}$, tal como lo explica RAMÓN para el caso de la ciudad de Lima, "Así como los hombres, también los animales y los objetos en general iban recibiendo su ubicación especifica de acuerdo a las nuevas pautas higiénicas" (RAMÓN, 1999: 310).

En el mismo bando se prohibía extraer barro de las calles para edificar, ya que "quedan lagunas y se abren pozos". ${ }^{21}$ Asimismo ordenaba sobre el aseo de la Plaza luego del mercadeo. Sin embargo, solo tres meses después: "Por cuanto por repetidos bandos de buen gobierno esta mandado se compongan las calles de esta ciudad y que no se eche basura a ellas ni se haga barro para ningún edificio pues de ello resulta el hacerse muchos pantanos y pozos poniéndose intratables de pasar por ellas...". ${ }^{22}$
18- Bando del gobernador J. de Andonaegui, Buenos Aires, 01-031748, $A G N-A-; I X-8-10-1$

Folio: 164 .

19- Bando del gobernador $J . d e$ Andonaegui, Buenos Aires, 01-03 1753, AGN-A-; IX-8-10-1 Folios: 385-386.

20- Bando del gobernador interino A de la Vega Buenos Aires, 21-021755, $A G N-A-; I X-8-10-2$ Folio: 94.

21-Bando del gobernador interino A. de la Vega, Buenos Aires, 21-021755, $A G N-A-; I X-8-10-2$ Folio: 95.

22- Bando del gobernador $J$ de Andonaegui, Buenos Aires, 27-05-1755, $A G N$-A-; $I X-8-10-2$ Folio: 106. 
$\overline{\text { 23- JOHNSON, } 1992 \text { pp., } 153-}$ 190.

24- Bando del gobernador P. de Cevallos, Buenos Aires, 13-031762 AGN $-A-I X-8-10-2$ Folio: 1762 AGN 304.

25- Bando del gobernador P. de Cevallos, Buenos Aires, 13-031762 AGN $-A-I X-8-10-2$ Folio: 305 .
Se vuelve evidente por un lado el incumplimiento de los anteriores bandos y por el otro que probablemente la infraestructura de la ciudad no estaba lo suficientemente preparada para responder al crecimiento que esta estaba experimentando. Ya que si bien se exigía a los vecinos que edificasen en los huecos, la ciudad carecía tanto de materiales para la construcción como de mano de obra disponible para esto, lo que volvía a estos servicios altamente $\operatorname{costosos}^{23}$. Al respecto, en el año 1762 durante el gobierno de Cevallos advertimos algunos pequeños pero notables cambios en el mandato. Tras señalar que las calles de la ciudad se hallaban intransitables en varias de sus partes, ordena y manda: “... que todos los vecinos dueños de casas de esta ciudad o las personas que las habitasen a cuenta de los alquileres hagan, si no la tuviesen hecha, en sus pertenencias una calzada de ladrillo o piedra de ancho de una vara fijando a trechos algunos postes para embarazar que pasen por ella a caballo...". ${ }^{24}$

Por un lado, extendía la responsabilidad más allá del pequeño grupo de propietarios y por el otro aparecía la preocupación por dividir el espacio de manera que quedase una parte reservada para los caballos para facilitar la circulación. A su vez ordenaba a los vecinos que compusieran los hoyos o pantanos de las calles, rellenándolos para que quedasen llanas. Si bien el mandato en sí no es novedoso, el gobernador estipulaba paso a paso el transporte de los materiales de modo que las obras se llevasen a cabo, comprometiendo en el proceso a diferentes actores: "Los dueños de las lanchas entreguen las piedras que fuesen necesarias (...) para (asegurar) que se ejecute esta obra y las otras mandadas por este bando. Los carreteros deberán transportar la piedra desde el riachuelo hasta los parajes que los mismos regidores les asignen y los dueños de dichas esquinas costearán lo demás, debiendo ejecutarse en el término de dos meses... ". ${ }^{25}$

\section{LA ORGANIZACIÓN DE LA POBLACIÓN}

Para comprender las constantes preocupaciones de parte de las autoridades por el aseo y la composición de los espacios compartidos de la ciudad, debemos tener en cuenta el salto poblacional que impactó a Buenos Aires desde mediados del siglo XVIII.

Como ya fue reseñado se produjo un incremento en la incorporación de esclavos, a lo que debemos sumar - desde la década de 1740 - un importante movimiento migratorio desde las zonas fronterizas de la campaña bonaerense, que se encontraban asediadas por la amenaza del malón indígena (SANTAMARÍA, 2000). Además un elemento que marcó el crecimiento poblacional fue el establecimiento de extranjeros, quienes fueron recurrentemente expulsados por bando a lo largo de los veinte años que nos ocupan. 


\section{Crecimiento y control de la vida urbana.} Un análisis de los bandos de Gobierno en el Buenos Aires colonial (1742-I762)

Durante este período, se elaboraron diversas medidas, ya sea para expulsar a los elementos considerados indeseables - fueran extranjeros, forasteros, negros y mulatos solteros o vagamundos-, como para lograr un control sobre la circulación, habitación y ocupación de los diversos individuos en el entramado urbano ${ }^{26}$.

En relación con los extranjeros, los mandatos emitidos correspondían a las órdenes reales que expresamente prohibían su instalación en las colonias americanas. En un primer momento se expulsaba tanto a aquellos casados como a los solteros, pero a partir de 1740 , luego de la intervención del Cabildo, la medida pasó a contemplar únicamente a los solteros (TAu AnZó́tegui, 1992a).

En $1743^{27}$, tras un nuevo bando de expulsión, el Cabildo volvió a intervenir, en esta ocasión en pos de la permanencia de aquellos extranjeros que se desempeñasen en oficios mecánicos. El pedido se fundamentaba en su utilidad y se explicitaban los beneficios que los mismos proveían a la ciudad, en arquitectura, carpintería, instrumentos musicales, herrería, sastrería, zapatería y platería (TAU ANZOÁTEGUI, 1992b: 284). Lo que nos permite pensar por un lado que el aporte de los extranjeros estaba ya incorporado a la vida de la ciudad y que fue un elemento importante del desarrollo urbano, y por el otro reflexionar en relación con las contradicciones que se presentaban entre los encargados del gobierno de la ciudad a la hora de definir el tipo de población al que se le permitía o no establecerse en ella.

Un año después se penalizó a aquellas personas que: "los abrigan o aceptan en sus $\operatorname{casas}^{\text {"28 }}$, lo que refuerza la idea de una cierta aceptación por parte de los porteños, como también de la posibilidad de cierto aprovechamiento de orden comercial, ya que las habitaciones eran alquiladas en beneficio de los propietarios.

Más allá de estas cuestiones, los bandos en este sentido se reiteran ${ }^{29}$. En $1745^{30}$, el gobernador Ortiz de Rozas, tras admitir el incumplimiento del anterior mandato de expulsión — de 1743 - y renovarlo, suma en este caso a los negros y mulatos solteros. Este bando nos invita a pensar tanto en el crecimiento de la población urbana - que no necesariamente se correspondía con el tipo de población que las autoridades estimaban como útiles - como en las contradicciones propias de la estructura laboral y del régimen esclavista.

Ya desde los primeros años de la conquista se había establecido, en todas las ciudades coloniales, la costumbre de alquilar esclavos para ganar jornales. Si bien el monto era repartido de manera desigual entre el amo y el esclavo, este último podía reunir los fondos para comprar su libertad. Además, el trabajo fuera de la casa del amo le significó una
26-Además, el tema de los extranjeros en particular representó una fuente de conflictos entre las mismas autoridades, ver TAU ANZOÁTEGUI, $1992 a$.

27- Bando del gobernador D. Ortiz de Rozas, Buenos Aires 05-04-1743, AGN - $A$-; IX-8-10-1 Folios: 21-22

28-Bando del gobernador $D$. Ortiz de Rozas, Buenos Aires, Ortiz de Rozas, Buenos Aires, 07-07-1744.

29- Cabe señalar en relación con los extranjeros que las medidas para limitar su participación en para limitar su participacion en los distintos aspectos de la vida
porteña estuvieron en gran medida ligadas con los sucesivos conflictos bélicos entre las coronas europeas.

30- Bando del gobernador D. Ortiz de Rozas, Buenos Aires, 06-07-1745 AGN - A- IX-8-10-1 Folio 68 . 
31- Bando del gobernador $J$. de Andonaegui, Buenos Aires, 22-06-1746, AGN -A-IX-8-10-1 Folio: 96.

32- Bando del gobernador $J$. de Andonaegui, Buenos Aires, 2206-1746, AGN -A-IX-8-10-1 Folio: 97 libertad mayor de circulación (Bernand, 2001). En Buenos Aires, el negro encontraba empleos y oficios de cierto rédito. Esta posibilidad de un cierto ascenso social tenía su raíz en la escasez de mano de obra en la ciudad, que conducía a amos de menores recursos al arrendamiento de sus criados o a la manumisión por cifras que atenuaban su liquidez (SANTAMARía, 2000). En este sentido, el hecho de que se expulsara a los negros y mulatos solteros nos estaría hablando de una intención por limitar estas posibilidades de circulación y ascenso social, que la misma estructura laboral de la ciudad facilitaba.

Que la expulsión remitiese a los solteros está en consonancia con el valor normativo que se asignaba en la época a la familia como columna vertebral de todo el armazón social, tanto en los sectores hegemónicos como en los subalternos (CICERCHIA, 2000). El matrimonio estaba ligado a la adquisición de cierta solvencia económica y una estabilidad residencial (Socolow 1990), con lo cual el mandato podría estar buscando limitar la cantidad de personas calificadas como "vagamundos" — personas sin oficio ni habitación conocida — que circulaban por la ciudad y que representaron una de las mayores preocupaciones para las autoridades locales.

En este sentido, recurrentemente se elaboraron bandos que ordenaban la expulsión de los "vagamundos", aunque decía el gobernador: “... no ha tenido efecto experimentándose cada día diferentes hurtos que no se pueden averiguar ni coger a los que los ejecutan sin embargo de haberse doblado las patrullas y rondas". ${ }^{31}$ En este bando, emitido por Andonaegui en 1746, se apelaba a la seguridad del vecindario, y la vagancia quedaba sin más asociada con el delito, no se buscaba expulsar al "ladrón" sino a los vagos, como condición que encarnaría la mayor de las amenazas. El documento continúa con una apelación al vecindario: “ ... y asimismo todos los vecinos y moradores de esta cuidad me darán parte y a las demás justicias de los parajes y casas en que se abrigasen los dichos vagamundos para que sean presos y remitidos (...) por ser esto en beneficio de la vecindad y seguro de sus casas...".32

Nuevamente podemos entrever el modo en que el gobierno requería de la intervención de los habitantes de la ciudad para limitar la participación de los vagamundos en la vida urbana, como también la existencia de casas donde se los "abrigaba". En relación con el tipo de gente forastera que arribaba a la ciudad en 1747 el gobernador advertía que "Por cuanto conviene el saber los forasteros que entran y salen de esta ciudad para que de esta suerte se venga en conocimiento de quienes son y si conviene o no se mantengan aquí, ordeno y mando a todos los vecinos que alquilan cuartos que den cuenta el nombre y procedencia 


\section{Crecimiento y control de la vida urbana.} Un análisis de los bandos de Gobierno en el Buenos Aires colonial (1742-I762)

de sus inquilinos (...) para que de esta suerte se sepa de la gente forastera que hubiese para que siendo perjudiciales con dicha noticia mandarlos salir de ella". ${ }^{33}$

Notamos que las autoridades vieron como necesario realizar un control tanto sobre la cantidad y la calidad de forasteros asentados en la ciudad como del espacio preciso que ellos ocupaban, y cómo además se buscaba evaluar y diferenciar a aquellos que pudieran representar algún beneficio para la ciudad de aquellos que no. Tal como fue expuesto, Buenos Aires requería tanto de especialistas mecánicos como de mano de obra en general, y en este sentido existían vínculos económicos entre los sujetos que eran expulsados y los porteños, con lo cual el cumplimiento estricto de las órdenes de expulsión se volvía dificultoso.

Un año después, en $1748^{34}$, vagos y extranjeros solteros quedaron unidos en un mismo mandato de expulsión. La orden se justificaba tanto en función de la seguridad como por la imposibilidad de lograr la aprehensión de los infractores. Estos mandatos nos estarían hablando de ciertos conflictos asociados, tanto con el crecimiento de la población, como con su ubicación específica dentro del entramado urbano, que las autoridades intentaron conocer y controlar, aunque no siempre con éxito. En el año 1750 el mandato se repetía. ${ }^{35}$

\section{LA SEGURIDAD URBANA DESDE LA PERSPECTIVA DEL GOBIERNO}

Como fue brevemente reseñado, diversos asuntos relativos a la organización de la vida urbana fueron objeto de pujas y tensiones entre los agentes del poder colonial. Las cuestiones relativas a la seguridad y al control de los sujetos en el entramado urbano no fueron la excepción. En este sentido, quisiéramos retomar un conjunto de bandos emitidos entre marzo y mayo de $1760^{36}$, que ejemplifican estas cuestiones a la vez que nos permiten avanzar en su análisis.

El 5 de marzo, Alonso de la Vega, a cargo interinamente del gobierno de la ciudad por ausencia de Pedro de Cevallos, publicó un bando en el que daba cuenta de la escalada de delitos que se sucedían y reclamaba a los alcaldes ${ }^{37}$ : "la correspondiente y pronta administración de justicia...". ${ }^{38}$ Un mes después, De la Vega intimó por medio de un bando a los escribanos públicos a que aceleren las causas judiciales, ya que por la demora: “... se originan graves e irreparables daños con la larga detención de estos reos en las prisiones los que motivados de esto escalan con frecuencia las cárceles haciendo fuga de ellas sin que se les imponga el castigo...". 39
33- Bando del gobernador J. de Andonaegui, Buenos Aires, 08-08 1747, AGN -A-IX-8-10-1 Folios. 140-141.

34- Bando del gobernador $J$ de Andonaegui, Buenos Aires 11-01-1748, A.G.N -A-IX-8-10-1 Folio: 153 .

35- Bando del gobernador $J$. de Andonaegui, Buenos Aires, 08-011750, A.G.N -A-IX-8-10-1 Folios: 270-272.

36- Cabe señalar que dicha documentación ha sido analizada por JOSE MARIA DIAZ COUSELO (1995) Un memorial sobre las causas criminales en Buenos Aires a mediados del siglo XVIII. Disponible en: http://www. bibliojuridica.org/libros/2/820/20. $p d f$.

37- Funcionarios del Cabildo.

38- Bando del gobernador interino A. de la Vega, Buenos Aires, 05-03 1760, $A G N-A-I X-8-10-2$ Folio 209.

39- Bando del gobernador interino A. de la Vega, Buenos Aires, 14-04 A. de la Vega, Buenos Aires, 14-04-
1760 , AGN -A-IX-8-10-2 Folio: 210. 
40- Memorial emitido por el Alguacil mayor del santo oficio y los Alcaldes de primer y segundo $A G N-A-I X-8-10-2$ Folio: 216

41- Memorial emitido por el Alguacil mayor del Santo Oficio y los Alcaldes de primer y segundo voto, Buenos Aires, 08-05-1760, voto, Buenos Aires, 08-05-1760 $A G N-A-I X-8-10-2$ Folio $: 217$.

Casi un mes después el bando se repitió de manera prácticamente idéntica. Observamos al gobernador preocupado por poner orden, tanto en lo que hace a la seguridad en calles y caminos, como en relación con la administración de la justicia. Apenas tres días después del segundo mandato, llegaba una larga respuesta de las mayores autoridades del Cabildo, encargadas de las cuestiones de justicia; el alguacil mayor del santo oficio y los alcaldes de primer y segundo voto. En ella daban cuenta de las dificultades con las que tenían que trabajar los jueces y comisionados y advertían: "Que en la cárcel se halle crecido número de reos es cierto como se le ha informado a (el gobernador) cuyo hecho se manifiesta en alguna parte el cumplir los alcaldes ordinarios con su obligación, pues siendo el número de gentes crecido y lo más de ella vulgar crecen a proporción los excesos y desórdenes que hacen necesaria la multitud de presos ". ${ }^{40}$

Los alcaldes se justificaban constantemente y buscaban sujetos en los cuales depositar las responsabilidades: "La frecuencia de los delitos en esta ciudad tenemos experimentado nace de algunos varios principios pues siendo (...) mucho lo que ha crecido el gentio y especialmente de estas gentes sin bienes ningunos, ni habitación fija ni conocida" ${ }^{41}$

Al exponer las razones por las que creció el delito, el peso recae indirectamente tanto en los extranjeros/forasteros, como en los que son clasificados de vagamundos. Aquel que no poseía bienes, oficio o domicilio reconocido era percibido como peligroso, precisamente porque representaba un elemento imposible de conocer y por ello controlar. RAMÓN para el caso de Lima sostiene que: "Condenando el nomadismo, se le otorgaba un determinado valor legal al espacio, transformando en ilegal a todo aquel que modificara el trayecto que estaba oficialmente registrado o, peor aún, que careciera de punto de referencia" (RAMÓN, 1999: 310).

De este modo asistimos a la apertura de un camino tendiente la persecución y consecuente criminalización de vagos y malhechores que encontraba eco justamente en la ideología vigente, según la cual a cada uno de los elementos que componían la sociedad debía corresponderle un determinado lugar dentro del espacio urbano.

La carta continuaba con las justificaciones por parte de los alcaldes y la alusión a que las penas vigentes no eran suficientes para poner fin a los desórdenes que experimentaba la ciudad. Seguramente hay algo de exageración en las repetidas menciones a los desórdenes; no debemos olvidar que es una carta por medio de la cual los alcaldes tratan de defender su posición. 


\section{Crecimiento y control de la vida urbana. Un análisis de los bandos de Gobierno en el Buenos Aires colonial (1742-I762)}

Para el presente análisis es relevante, ya que nos permite observar varias cuestiones. Por un lado vemos en funcionamiento la puja entre funcionarios. La administración de la justicia corría por cuenta del Cabildo tanto en materia civil como criminal, pero en este caso el gobernador presionaba por un funcionamiento más eficiente, con lo que podemos pensar en un intento de centralización política, aunque la misma fuera resentida ya sea con el incumplimiento en relación con lo mandado o con la declaración de los alcaldes. Por otro lado, su larga justificación nos permite observar de qué modo eran percibidos por los porteños el crecimiento y la circulación de la población en el entramado urbano, o por lo menos cómo la elite encargada del gobierno y justicia de Buenos Aires empezó a formarse una idea con respecto al origen del desorden, que no estaría en el orden social en sí, sino en el tipo de crecimiento poblacional que iba adquiriendo la ciudad y la consecuente ocupación y transformación de los diversos espacios urbanos. De este modo, desde la perspectiva del gobierno, para transformar esta situación no era necesario un cambio en el orden de las cosas, sino un mayor control de las personas y sus actividades.

\section{REFLEXIONES FINALES}

Como ya fue mencionado, a mediados del siglo XVIII Buenos Aires conoció un crecimiento sin precedentes tanto a nivel económico, político administrativo, como poblacional, todo lo cual generó conflictos y transformaciones que requirieron soluciones acordes. En este escenario, los gobernadores buscaron organizar un poder más centralizado que les permitiera controlar y organizar tanto los espacios urbanos como el tipo de población asentada allí.

En este trabajo concentramos nuestra atención en los veinte años que suceden al momento en que los gobernadores comenzaron a emitir con mayor frecuencia bandos tendientes a la organización de la vida urbana, para poder observar cuáles eran sus principales preocupaciones y a qué tipo de soluciones se apelaba en cada caso.

En este sentido, pudimos observar cómo en relación con la organización de los espacios de la ciudad recurrentemente se buscó legislar y ordenar tanto el aseo, como la compostura de las calles y de los solares vacíos. Estas cuestiones se justificaban en función de la seguridad del vecindario, ya sea porque los aires podían perjudicar la salud, como porque aquellos espacios "vacios" servían para "cometerse en ellos maldades". Lo cual se encontraba íntimamente vinculado con el crecimiento poblacional que vivía Buenos Aires y con el modo en que eran percibidos muchos de los sujetos que allí arribaban. El control 
de los espacios cobraba sentido en la medida en que estos eran ocupados y resignificados por los diversos grupos que componían la sociedad porteña. Como fue mencionado, las particularidades de la vida urbana se contradecían con el ideal estatutario según el cual a cada uno de los grupos sociales le correspondía un determinado lugar en el espacio. Por otro lado, por las características propias de su estructura laboral, Buenos Aires requería de la participación de individuos dispuestos a realizar tareas manuales - ya fueran especialistas en diversos oficios, como proveedores, vendedores, sirvientes o esclavos- - y en este sentido las regulaciones en torno de su participación alrededor del entramado urbano fueron difícilmente respetadas. De hecho, la recurrencia con que fueron tratados ciertos temas en la documentación da cuenta de los repetidos incumplimientos.

A lo largo de los años, los gobernadores buscaron un seguimiento más estricto en relación con las problemáticas que hemos analizado. Tanto en función de la construcción de los solares vacíos, como en relación con la búsqueda de un conocimiento pormenorizado sobre las características de los forasteros que llegaban a la ciudad. En este sentido, el vagamundo - como individuo sin oficio, bienes o residencia fija - se constituyó en el paradigma de lo incontrolable y en la razón última de los males que aquejaban a la ciudad.

Por último, en relación con las pujas entre las autoridades del Cabildo y la figura del gobernador, podemos observar cuáles eran las percepciones de la época en torno a las razones por las cuales había aumentado el delito en la ciudad.

Como consideramos a la ciudad en sí misma como "un espacio compartido" donde imperaba la costumbre, entendemos que en este período no solo se buscaba imponer la presencia de un gobierno, sino también "construir una ciudad" y normatizar la convivencia, todo ello en medio de una fase de crecimiento. Buenos Aires se desarrollaba más allá de los márgenes esperables, y en este contexto se desplegó dentro del cuerpo social toda una gama de posicionamientos en torno del tipo de "control" que se intenta implementar, entre lo esperado, lo tolerable y lo inevitable. Así como entre las posibilidades concretas y los intereses en disputa. Justamente porque el tipo de desarrollo por el que transitaba la ciudad y su sociedad urbana chocaban con el ideal estatutario vigente y su consecuente transposición espacial. 


\section{Crecimiento y control de la vida urbana. Un análisis de los bandos de Gobierno en el Buenos Aires colonial (I742-I762)}

\section{BIBLIOGRAFÍA}

ARECES, Nidia (2000). “Las sociedades urbanas coloniales”. En TANDETER, E. (Dir.), Nueva historia Argentina, la sociedad colonial, Tomo II. Ed. Sudamericana, pp. 145-187, Buenos Aires.

BARRENECHE, Osvaldo (2001) Dentro de la ley, todo. La justicia criminal de Buenos Aires en la etapa formativa del sistema penal moderno de la Argentina. Ed. Al margen, La Plata, Argentina.

BEATO, Guillermo (2005). "La época colonial entre los años 1600-1750. En: Assadourian, C, Beato, G y Chiaramonte, J: Historia argentina II. De la conquista a la independencia, pp. 117-275. Ed. Paidós, Buenos Aires.

BERNAND, Carmen (1997) Historia de Buenos Aires. Fondo de Cultura Económica, Buenos Aires.

BERNAND, Carmen (2003) Negros esclavos y libres en las ciudades hispanoamericanas. Fundación histórica, Tavera, Madrid.

CICERCHIA, Ricardo (2000). "Formas y estrategias familiares en la sociedad colonial", En: Tandeter, E. (Dir.). Nueva historia Argentina, la sociedad colonial, Tomo II. Ed. Sudamericana, pp. 331-353. Buenos Aires.

CHIARAMONTE, José Carlos (2005). "La etapa ilustrada 1750-1806. En: Assadourian, C, Beato, G y Chiaramonte, J: Historia argentina II. De la conquista a la independencia, pp. 281-369. Ed. Paidós, Buenos Aires.

DE SOLANO, Francisco (1990) Las ciudades hispanoamericanas y pueblos de indios. Consejo Superior de Investigaciones Científicas, Madrid.

DÍAZ COUSELO, José María (1995) Un memorial sobre las causas criminales en Buenos Aires a mediados del siglo XVIII. Disponible en: http://www.bibliojuridica.org/ libros/2/820/20.pdf.

GUTMAN, Margarita y Jorge HARDOY (1992) Buenos Aires. Historia urbana del área metropolitana. Ed. Mapfre, Madrid.

HOBERMAN, Louise y Susan SOCOLOW (1992) Ciudades y sociedad en Latinoamérica colonial. Fondo de Cultura Económica, Buenos Aires.

JOHNSON, Lyman y Susan SOCOLOW (1980). "Población y espacio en el Buenos Aires del siglo XVIII" En: Desarrollo económico, 20:79, octubre-diciembre, pp. 329-349. Buenos Aires. LOCKART, James (1982) El mundo Hispanoperuano. 1536-1560. Fondo de Cultura Económica, México.

MARTIRÉ, Eduardo y Víctor TAU ANZOÁTEGUI (2003) Manual de historia de las instituciones argentinas. Histórica, E. Perrot, Argentina. 
MORNER, Magnus (1959). "Panorama de la sociedad del Río de la Plata durante la primera mitad del siglo XVIII". En: Estudios Americanos. Número 92-93, Sevilla.

MILLETICH, Vilma (2000). "El Río de la Plata en la economía colonial”, En Tandeter, E. (Dir.) Nueva historia Argentina, la sociedad colonial, Tomo II, Ed. Sudamericana, pp.: 189-249, Buenos Aires.

MORSE, Richard (2004). "El desarrollo urbano de la Hispanoamérica colonial”. En Sánchez Albornoz, N. et al.: América Latina en la época colonial. Tomo II: Economía y sociedad, pp. 273-306. Ed. Crítica, Barcelona.

MOUTOUKIAS, Zacarías (2000). “Gobierno y sociedad en el Tucumán y el Río de la Plata, 1550-1800”. En: Tandeter, E. (Dir.) Nueva historia Argentina, la sociedad colonial, Tomo II. Ed. Sudamericana, pp. 355-411, Buenos Aires.

OTS CAPDEQUÍ, José María (1940). "Los portugueses y el concepto jurídico de extranjería en los territorios hispanoamericanos durante el período colonial”. En: Estudios de Historia del Derecho Español en Indias, Bogotá.

PÉREZ CANTÓ, María Pilar (1985) Lima en el siglo XVIII. Estudio socioeconómico. Ediciones de la Universidad Autónoma de Madrid, Madrid.

RAMÓN, G (1999). "Urbe y orden: evidencias del reformismo borbónico en el tejido limeño”. En: El Perú en el siglo XVIII. La era borbónica, O’Phelan Godoy, S. (Comp.). Pontificia Universidad católica del Perú. Instituto Riva-Agüero, pp. 295-324, Perú.

RAMOS GOMÉZ, Luis. (2005). “Enfrentamientos entre grupos de poder por el dominio del Cabildo de Quito entre 1735 y 1739”. En: Revista complutense de historia de América. Vol. 31 53-77.

ROMERO, José Luis (2001) Latinoamérica: las ciudades y las ideas. Siglo veintiuno editores, Buenos Aires.

RUIBAL, Beatriz (2000). “Cultura y política en una sociedad de antiguo régimen”. En: Tandeter, E (dir) Nueva historia Argentina, la sociedad colonial, Tomo II. Ed. Sudamericana, pp. 413-444, Buenos Aires.

SANTAMARÍA, Daniel (2000). "La población: estancamiento y expansión, 1580-1855" En: Romero, J. L. y L. A. Romero (Dir.) Buenos Aires historia de cuatro siglos, Tomo I. Ed. Altamira, pp. 211-223, Buenos Aires.

SOCOLOW, Susan (1987) The bureaucrats of Buenos Aires, 1769-1810: amor al real servicio.

Duke University Press. Londres.

SOCOLOW, Susan (1990). "Parejas bien constituidas: la elección matrimonial en la Argentina colonial, 1778-1810”. En: Anuario del IEHS, pp. 133-160. Tandil.

SOCOLOW, Susan (1991) Los mercaderes del Buenos Aires virreinal: familia y comercio. Ediciones De la Flor, Buenos Aires. 
Crecimiento y control de la vida urbana. Un análisis de los bandos de Gobierno en el Buenos Aires colonial (1742-1762)

TAU ANZOÁTEGUI, Víctor (1976). “La costumbre en el siglo XVIII. Doctrina jurídica y praxis rioplatense a través de los Cabildos". En: Memoria del IV Congreso Internacional de Historia del Derecho Indiano. UNAM, México.

TAU ANZOÁTEGUI, Víctor (1992a). "Los bandos de buen gobierno de Buenos Aires en la época hispánica”. En: Tau Anzoátegui, V: La ley americana en América hispana. Del descubrimiento a la emancipación. Cap. X. Academia Nacional de la Historia, Buenos Aires.

TAU ANZOÁTEGUI, Víctor (1992b). "Una defensa de los extranjeros en el Buenos Aires de 1743" En: Tau Anzoátegui, V: La ley americana en América hispana. Del descubrimiento a la emancipación. Cap. VII. Academia Nacional de la Historia, Buenos Aires.

\section{Documentación inédita}

Archivo General de la Nación (Argentina):

Sala IX, gobierno colonial.

Bandos de los Gobernadores del Río de la Plata

Ubicación: 9-8-10-1: 1741-1752.

Ubicación: 9-8-10-2: 1753-1763. 
